\title{
Absence of zoonotic Bartonella species in questing ticks: First detection of Bartonella clarridgeiae and Rickettsia felis in cat fleas in the Netherlands
}

Ellen Tijsse-Klasen ${ }^{1}$, Manoj Fonville ${ }^{1}$,Fedor Gassner ${ }^{3}$, Ard M Nijhof ${ }^{6,7}$, Emil KE Hovius ${ }^{4}$, Frans Jongejann ${ }^{6}$, Willem Takken ${ }^{3}$, Johan R Reimerink ${ }^{2}$, Paul AM Overgaauw ${ }^{5^{*}}$ and Hein Sprong ${ }^{1^{*}}$

\begin{abstract}
Background: Awareness for flea- and tick-borne infections has grown in recent years and the range of microorganisms associated with these ectoparasites is rising. Bartonella henselae, the causative agent of Cat Scratch Disease, and other Bartonella species have been reported in fleas and ticks. The role of Ixodes ricinus ticks in the natural cycle of Bartonella spp. and the transmission of these bacteria to humans is unclear. Rickettsia spp. have also been reported from as well ticks as also from fleas. However, to date no flea-borne Rickettsia spp. were reported from the Netherlands. Here, the presence of Bartonellaceae and Rickettsiae in ectoparasites was investigated using molecular detection and identification on part of the gltA- and $16 \mathrm{~S}$ rRNA-genes.

Results: The zoonotic Bartonella clarridgeiae and Rickettsia felis were detected for the first time in Dutch cat fleas. B. henselae was found in cat fleas and B. schoenbuchensis in ticks and keds feeding on deer. Two Bartonella species, previously identified in rodents, were found in wild mice and their fleas. However, none of these microorganisms were found in 1719 questing Ixodes ricinus ticks. Notably, the gltA gene amplified from DNA lysates of approximately $10 \%$ of the questing nymph and adult ticks was similar to that of an uncultured Bartonella-related species found in other hard tick species. The gltA gene of this Bartonella-related species was also detected in questing larvae for which a 165 rRNA gene PCR also tested positive for "Candidatus Midichloria mitochondrii". The gltA-gene of the Bartonella-related species found in I. ricinus may therefore be from this endosymbiont.
\end{abstract}

Conclusions: We conclude that the risk of acquiring Cat Scratch Disease or a related bartonellosis from questing ticks in the Netherlands is negligible. On the other hand fleas and deer keds are probable vectors for associated Bartonella species between animals and might also transmit Bartonella spp. to humans.

\section{Background}

Bartonella species are facultative intracellular Gramnegative bacteria which can infect humans and a wide range of animal species. Cat-scratch disease (CSD) is probably the most common Bartonella infection in the northern hemisphere [1,2]. The hallmark of CSD is enlargement and tenderness of lymph nodes draining

\footnotetext{
* Correspondence: P.A.M.Overgaauw@uu.nl; HSprong@gmail.com 'Laboratory for Zoonoses and Environmental Microbiology, National Institute for Public Health and Environment (RIVM), Bilthoven, The Netherlands ${ }^{5}$ Institute for Risk Assessment Sciences, Division of Veterinary Public Health, Utrecht University, Utrecht, The Netherlands

Full list of author information is available at the end of the article
}

the site of inoculation of the microorganism [3]. Regional lymphadenopathy usually develops 2 to 3 weeks after exposure and normally resolves spontaneously after several months [4]. Thirty percent of the patients report low-grade fever and a skin or mucous membrane lesion may be observed at the site of inoculation for $25 \%$ to $>90 \%$ of patients [3,5]. Extranodal clinical manifestations, such as encephalopathy, neuroretinitis, arthritis, and lytic bone lesions, occur in approximately $10 \%$ of patients [3,5-8]. Furthermore, Bartonella spp. are an important cause for blood-culture negative endocarditis [9-11]. Disease symptoms depend on the immune status of the host; in immuno-compromised hosts, the bacteria 
are often present in blood and involved in angioproliferative disorders such as bacillary angiomatosis and peliosis hepatis [12]. The domestic cat is the major reservoir of Bartonella henselae, with a confirmed link to disease in humans $[13,14]$. Infected cats are usually asymptomatic and develop relapsing bacteraemia for long periods [15]. In a Dutch study, half of the cats were serological positive, and $22 \%$ were found to have a B. henselae bacteremia [16]. Bites or scratches from infected cats are associated with development of CSD. Cat fleas, Ctenocephalides felis, are involved in transmission between cats and may be also able to transmit $B$. henselae to humans: Approximately 30\% of patients with CSD do not recall traumatic cat contact [17-19]. Solid evidence to support transmission via cat fleas is lacking. Other Bartonella species, including Bartonella clarridgeiae and Bartonella grahamii, have also been linked to human disease. However, there are only few reports of disease cases linked to these species [20-23].

The number of cases with tick-borne diseases in the Netherlands is on the rise [24]: This is illustrated by the fourfold increase in reported cases of erythema migrans since 1994, up to 22,000 patients in 2009 . The most straightforward explanation is the reported increase in the incidence of tick bites [24]. The same tick species transmitting the etiologic agents of Lyme disease may also serve as vector of the causative agent of CSD and maybe also other Bartonella species [25-27]. Several PCR-based studies have demonstrated $B$. henselae DNA in various Ixodid tick species [26,28-32]. A recent study demonstrated that $B$. henselae can be transmitted across the developmental stages of Ixodes ricinus [33]. Altogether, these studies imply that CSD can be acquired from ticks, but studies contradicting this conclusion have also been published [34]. One of the aims of this study is to investigate whether Bartonellaceae, particularly $B$. henselae, are present in $I$. ricinus ticks in the Netherlands and form a risk to public health.

Another class of pathogens that can be transmitted by both Ixodid ticks and cat fleas is Rickettsiae. They are fastidious, mostly obligate intracellular alpha-proteobacteria. Hard ticks (Ixodidae) have been identified as vectors of the spotted fever syndrome in humans, which is caused by at least 15 different Rickettsia species [35]. Two infamous members of this group are Rickettsia rickettsii, the causative agent of Rocky Mountain spotted fever, and Rickettsia conorii, the causative agent of Mediterranean spotted fever [36]. Rickettsia helvetica is the most prevalent rickettsial species found in I. ricinus ticks in the Netherlands $[37,38]$. To date, the pathogenic potential of $R$. helvetica is unclear but infection with $R$. helvetica has been suspected in acute perimyocarditis, unexplained febrile illness, sarcoidosis and recently also meningitis [39-47]. Laboratory diagnosis of rickettsioses is predominantly based on serology. Currently, microimmunofluorescence is considered as a reference serological assay, but most commercially available tests offer a very limited set of antigens, mostly $R$. rickettsii and/or $R$. conorii, and serological cross-reaction with other rickettsial pathogens are common. Notably, some patients suspected to have (suffered from) a (mild) rickettsiosis do not recall a tick bite. In these cases, other potential sources of infection, for example cat fleas, might be involved. Cat fleas may maintain and transmit Rickettsia felis which is the causative agent of flea-borne spotted fever, also called cat flea typhus or summer flu [48]. Clinical signs are similar to those of murine typhus and other febrile illnesses [49]. Patients usually have fever, fatigue, headache, myalgia, rash and elevation of liver enzymes, although these clinical manifestations do not occur in all patients. They can also present abdominal pain, pleuric chest pain, diarrhea, nausea, vomiting, conjunctivitis, and neurological symptoms [50-54]. R. felis appears to have a global distribution [48], and it is not unlikely that $R$. felis is also present in the Netherlands. Nevertheless, evidence for the presence of R. felis in Dutch cat fleas is lacking and no autochthonous clinical cases of flea-borne rickettsisos have been reported. In this study, we investigated whether $R$. felis is present in Dutch cat fleas.

\section{Methods}

Collection of ticks, fleas, deer keds and wildlife samples Nymphs and adult ticks were collected for recent studies between 2006 and 2010 by flagging vegetation at 16 different locations in The Netherland (Table 1). Additionally, questing ticks from all stages were collected from vegetation in Vrouwenpolder in October 2010.

Ticks from cats were collected by veterinarians between 2006 and 2009 as described [55]. More than 200 veterinarian clinics expressed interest in the study and were supplied with information packages containing posters, brochures and collection tubes. Participating clinics were asked to record host species, residence area of the pet owner, date of collection and whether the pets had travelled outside the Netherlands recently.

Deer keds (Lipoptena cervi) and attached ticks were collected from red deer by hunters.

All ticks used for this study were identified as Ixodes ricinus according to current keys, and life stage and sex of the ticks were recorded.

Tissue samples (ears) were collected from wood mice caught in Duin and Kruidberg area [37].

Fleas from bank voles (Myodes glareolus) and wood mouse (Apodemus sylvaticus) were derived from a previous study [37].

Fleas from 109 cats and 44 dogs were collected by 15 veterinary clinics and volunteers throughout the 
Table 1 Geographic distribution of questing I. ricinus ticks (nymphs and adults)

\begin{tabular}{llll}
\hline Location & (Previous study) & Ticks (n) & Bartonella-related spp. (EF662054) \\
\hline Apeldoorn & Gassner et al., 2010 [74] & 40 & 4 \\
Bergherbos & Tijsse-Klasen et al., 2010 [38] & 17 & 0 \\
Duin en Kruidberg & Sprong et al., 2009 [37] & 157 & 36 \\
Ede & Gassner et al., 2010 [74] & 271 & 14 \\
Eijsden & Gassner et al., 2010 [74] & 49 & 2 \\
Gieten & Gassner et al., 2010 [74] & 22 & 1 \\
Haaksbergen & Gassner et al., 2010 [74] & 15 & 0 \\
Heumensoord & Tijsse-Klasen et al., 2010 [38] & 67 & 5 \\
Hoog Baarlo & Gassner et al., 2010[74] & 221 & 12 \\
Hullenberg & Tijsse-Klasen et al., 2010 [38] & 60 & 6 \\
Kwade Hoek & Gassner et al., 2010 [74] & 122 & 15 \\
Leusderheide & Tijsse-Klasen et al., 2010 [38] & 140 & 12 \\
Twiske & Gassner et al., 2010 [74] & 167 & 25 \\
Veldhoven & Gassner et al., 2010 [74] & 16 & 1 \\
Wassenaar & Gassner et al., 2010 [74] & 67 & 3 \\
\hline Vrouwenpolder & This study & 96 & $\mathbf{1 7}$ \\
\hline Total & & $\mathbf{1 5 2 7}$
\end{tabular}

Tick lysates were tested for the presence of Bartonella DNA using the gltA-primers. Samples were analysed by gel electrophoresis. PCR products of 380 bp were sequenced. Only Bartonella-related DNA sequences <99\% similar to EF662054 were detected.

Netherlands between October 2009 and October 2010. Fleas were identified according to current taxonomic keys and pools of fleas were formed per host animal and per flea species.

Ticks, fleas and deer keds were immersed in $70 \%$ ethanol immediately after collection and stored at $-20^{\circ} \mathrm{C}$ until DNA extraction.

\section{DNA extraction}

DNA from vegetation ticks, dear keds and fleas collected from cats and dogs was extracted by alkaline lysis as described earlier [56]. DNA of engorged ticks was extracted using the Nucleospin Tissue kit (MachereyNagel, Düren, Germany) following the manufacturer's protocol for the purification of genomic DNA from insects. DNA of fleas from a previous study was extracted by disruption in liquid nitrogen with pestles followed by homogenization in $600 \mu \mathrm{l}$ buffer RLT using a Qiashredder homogenizer according to the manufacturer's instructions (RNeasy minikit, Qiagen). DNA was extracted from $300 \mu \mathrm{l}$ homogenate using the QIAamp DNA mini kit (Qiagen). DNA was eluted in $50 \mu \mathrm{l}$ elution buffer. DNA of tissue samples from mice was extracted with the DNeasy Blood and Tissue kit (Qiagen, Hilden, Germany) according to the manufacturer's instructions.

\section{PCR-detection of Bartonella spp}

Nymphal and adult vegetation ticks, larvae from Vrouwenpolder, ticks collected from cats and deer, deer keds, rodent tissue samples, fleas collected from rodents and pet animals were tested for the presence of Bartonella spp.. Bartonella spp. DNA was detected by PCR followed by sequencing as previously described (59). Briefly, the gltA gene was amplified using 5'-GGGGACCAGCTCAtGGTGG and 5'-AATGCAAAAAGAACAGTAAACA as primers, yielding amplification products of approximately 380 base pairs. A serial dilution of the cultivated $B$. henselae ATCC 49882 strain was used as positive control [57]. The highest dilution was used as a positive control in PCR and to spike tick- and flea lysates to identify samples that contain PCR-inhibitory components. Inhibition was negligible in all tick and flea samples. PCR amplification of parts of the $16 \mathrm{~S}$ rRNA gene was done exactly as described by García-Esteban and colleagues, using $16 \mathrm{~S}-\mathrm{R}$ and P24Emod as primer pairs [58].

\section{PCR-detection of Rickettsia spp}

Tickets collected from cats as well as fleas from dogs and cats were tested for the presence of Rickettsia spp. DNA by PCR followed by reverse line blotting (RLB) as previously described [38] but with minor modification (Figure 1). Briefly, the 16S rRNA gene was amplified using 5'-AACGCTATCGGTATGCTTAACA and 5'-Biotin-ACTCACTCGGTATTGCTGGA as primers. For RLB analysis the following amino labeled probes were used: 5'-TTTAGAAATAAAAGCTAATACCG (catch all), 5'-CTTGCTCCAGTTAGTTAGT ( $R$. conorii), 5'GCTAATACCATATATTCTCTATG ( $R$. helvetica), 5'GTATATTCTCTACGGAAAAAAG (Rickettsia $s p$. IRS3), and 5'-TATATTCTCTACAGAGGAAAGATT $(R$. 


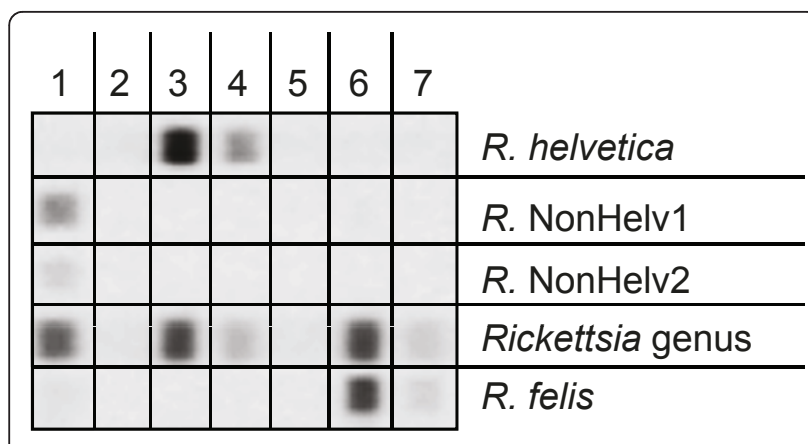

1: Rickettsia sp. positive tick

2: Rickettsia negative tick

3: $R$. helvetica positive tick

4: $R$. helvetica positive tick

5: Rickettsia negative flea

6: R. felis positive flea

7: $R$. felis positive flea

Figure 1 Reverse Line Blot with R. helvetica, non-helvetica and $R$. felis probes. PCR against a fragment of the 16S rRNA gene of Rickettsia was performed and samples were subjected to RLB as describe in the Methods section. Specificity of the probes is shown.

felis). In order to detect potential double infections of ticks with $R$. helvetica and other rickettsial species, two RLB probes which were able to hybridize to DNA of most Rickettsia species except for R. helvetica: 5'AATACCGTATATTCTCTACGGA (NonHelv1) and 5'AATACCGTATATTCTCTGCGGA (NonHelv2). Plasmids containing a 16S rRNA sequence from $R$. helvetica, $R$.conorii, $R$. typhi or $R$. prowazekii were used as positive controls.

Amplification of parts of the citrate synthase gene was done as described by De Sousa and colleagues using $\operatorname{cs} 409 \mathrm{~d} / \mathrm{rp} 1258 \mathrm{n}$ and $\operatorname{cs} 535 \mathrm{~d} / \mathrm{rp} 1258 \mathrm{n}$ as primer pairs [59].

\section{PCR detection of (Candidatus) Midichloria mitochondrii and phylogenetic analyses}

Part of the 16S rRNA gene of " $\mathrm{Ca}$. Midichloria mitochondrii" was amplified from tick lysates of larvae collected in Vrouwenpolder as described [60], using 5'GCTACAGCTCTTGCCCGT (IrESF) and 5'-CAAAAC CGACTCCCATGGC (IrESR) as primers. PCR amplicons were purified with the Qiaquick gel extraction kit (Qiagen Inc.) and sequenced using an ABI PRISM BigDye Terminator Cycle sequencing Ready Reaction kit (Perkin Elmer, Applied Biosystems). All sequences were confirmed by sequencing both strands. Sequences were compared with sequences in Genbank using BLAST. Phylogenetic analysis was performed using Bionumerics version 6.1 (Applied Maths, Gent, Belgium). Reference sequences were retrieved from Genbank. Sequences were aligned using Clustal $\mathrm{X}$ and distance-based analyses were conducted using Kimura 2-parameters distance estimates and trees were constructed using the Neighbour-Joining (NJ) algorithm, implemented in the MEGA program version 4.0. Bootstrap proportions were calculated by the analysis of 1000 replicates for $\mathrm{NJ}$ trees.

With the exception of the 16S rRNA PCR done for Rickettsia sp., which were analyzed by RLB, all PCR products were separated and analyzed by TAE agarose gelelectrophoresis. To minimize cross contamination and false-positive results, positive and negative controls were included in each batch tested for Bartonella or Rickettsia by the PCR. In addition, DNA extraction, PCR mix preparation, sample addition, and PCR analysis were performed in separated, dedicated labs.

\section{Results}

Vegetation ticks

To investigate the presence of Bartonella henselae in the Dutch tick population 1527 Ixodes ricinus nymphal and adult ticks from 16 geographically different locations were collected from recent field studies (Table 1).

Vegetation types of most sampling areas have been described previously with the exception of Vrouwenpolder. Vrouwenpolder is a vegetation rich dune area with several species of deciduous trees and shrubs and approximately $70 \%$ of the soil was covered with vegetation litter. Only very scarce and incomplete information is available about the fauna of all locations. Nymphs (98\%) and adults (2\%) were tested for Bartonella spp. by PCR on the gltA gene. PCR products of the expected size of approximately $380 \mathrm{bp}$ were observed in 177 tick lysates. Sequencing was successful on 98 of these samples. Except for five sequences with one or two point mutations, all these sequences were identical, and 99$100 \%$ homologous (372 bp) to an uncultured Bartonella-related sp. isolate from I. scapularis (Genbank accession number EF662054). Neither B. henselae nor any other Bartonella species were detected in any of the lysates of these questing ticks.

Next, lysates from 192 questing I. ricinus larvae from Vrouwenpolder were subjected to the same PCR against the gltA-gene. 41 larvae were positive and their sequences were identical to the Bartonella-related sp. from nymphs and adults. Under normal conditions, questing larvae have not yet had a blood meal. Transstadial but not transovarial (vertical) transmission of Bartonella has been described in ticks [33]. Therefore, it is unlikely that the Bartonella-related sp. in larvae is directly derived from a vertebrate host. The sequences of the Bartonella-related sp. might be derived from another microorganism present in ticks, which is capable of vertical transmission. This is supported by the fact that gltA-gene of this Bartonella-related sp. does 
not cluster with other Bartonella species (Figure 2). Therefore, the presence of the endosymbiont " $\mathrm{Ca}$. Midichloria mitochondrii" in the same larval tick lysates was tested by PCR and sequencing using primers specifically against part of the $16 \mathrm{~S}$ rRNA gene of " $\mathrm{Ca}$. Midichloria mitochondrii" [61]. 56 tick lysates yield a PCR product of the expected size (1250 bp), which successful sequences $(n=43)$ were all identical to sequences designated to "Ca. Midichloria mitochondrii" (AJ566640). An additional, independent PCR using generic primers on the 16S rRNA of Bartonella species was performed [58] on the same 192 samples. Five of these samples yielded a PCR product of the expected size $(440 \mathrm{bp})$. Sequencing of these products yielded 5 identical sequences (372 bp) which were $99 \%$ similar to a plethora of uncultured bacteria in Genbank, varying from an uncultured Bartonella isolated from the gut of Apis mellifera mellifera (EU055544), Phyllobacterium myrsinacearum (HQ380017) to a presumed Bartonella grahamii isolated from Apodemus agrarius (AB529498). As so many different microorganisms had similar homology, we concluded that this part of $16 \mathrm{~S}$ rRNA gene is not suitable for detection and identification of Bartonella species.
Ticks from cats

As domestic cats are the major reservoir host of $B$. henselae, adult ticks may acquire this pathogen while feeding on cats. 265 adult $I$. ricinus ticks removed from domestic cats were tested by PCR. B. henselae could not be detected in any of these tick lysates. In 56 lysates a fragment of approximately 380 bp was observed. Sequencing revealed that these samples contained the same Bartonella-related $s p$. as found in questing ticks (Table 2). The tick lysates from cats were also tested for Rickettsiae by PCR [62]. PCR products were analyzed by Reverse Line Blotting (RLB), which could differentiate several Rickettsia species, including $R$. felis (Figure 1). In 215 lysates $R$. helvetica was detected (Table 2). No other Rickettsia species were identified.

\section{Deer keds and ticks from deer}

The absence of Bartonella in questing ticks seemed contradictory to previous findings in the Netherlands [63], where more than $70 \%$ of the ticks collected from red deer were positive for Bartonella or closely related species. Therefore, 96 lysates from adult ticks fed on red deer were analysed by PCR on the gltA gene. Indeed,
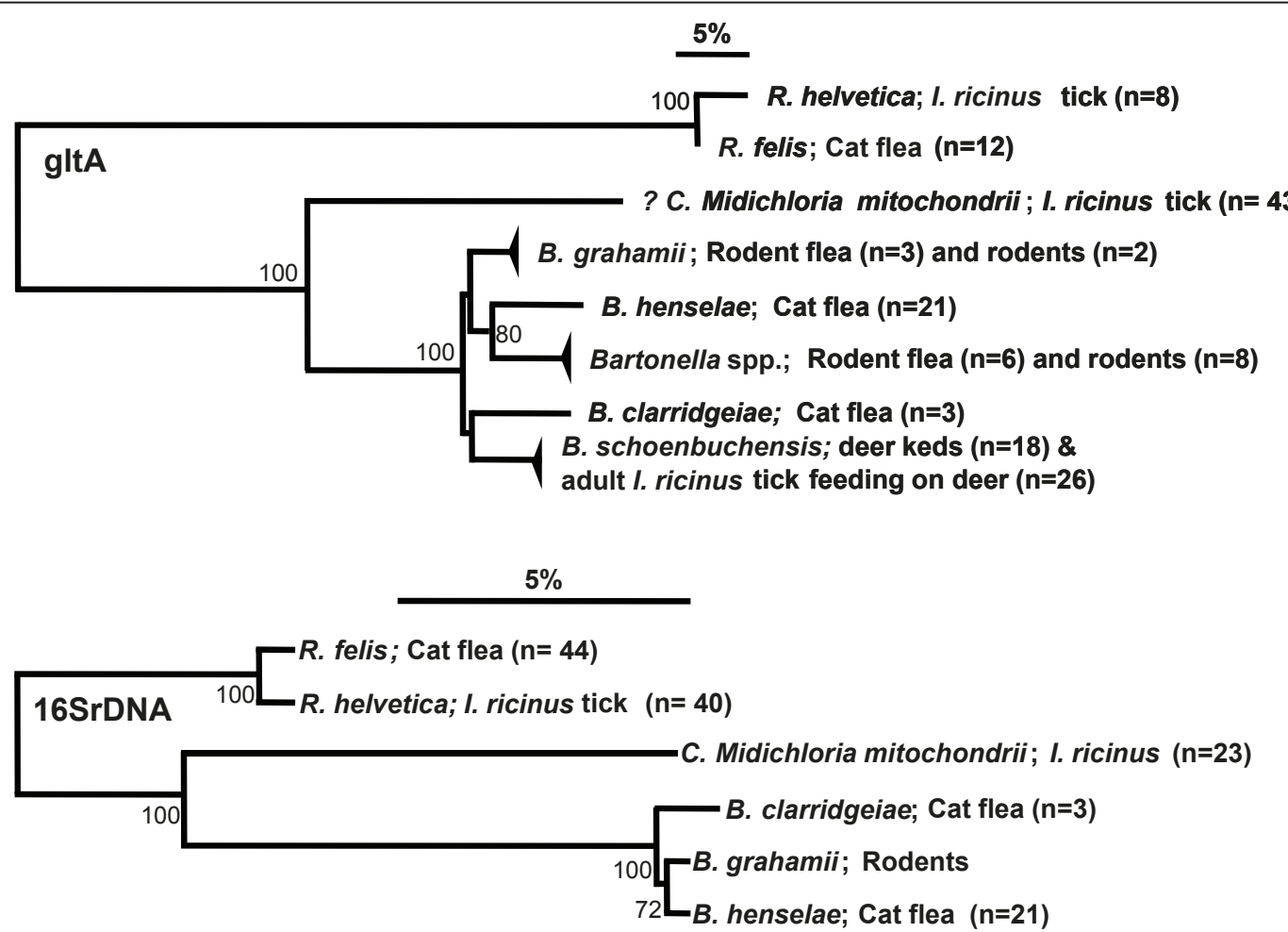

Figure 2 Phylogenetic analysis of the microorganisms found in ectoparasites. Neighbor-joining trees were based on the fragments of the gltA and $16 \mathrm{~S}$ rRNA genes of the microorganisms found in the ectoparasites and rodents described in this study. Sequences were aligned and analysed as described in the Methods section. The number of sequenced isolates is between brackets. Small triangles indicate less than $1 \%$ variation. Only bootstrap values $>75$ are indicated. The Bartonella-related sp. found in $\sim 10 \%$ of the questing ticks is indicated in the gltA-tree as "? Ca. Midichloria mitochondrii". 
Table 2 Bartonella and Rickettsia in ticks feeding on cats

\begin{tabular}{ll}
\hline Microorganism (DNA) & Positive ticks (\%) \\
\hline Bartonella henselae & $0(0-1.4 \%)$ \\
Bartonella-related $s p$. & $56(16-27 \%)$ \\
Rickettsia helvetica & $215(76-86 \%)$ \\
Rickettsia felis & $0(0-1.4 \%)$ \\
\hline Number of ticks tested & $\mathbf{2 6 5}$
\end{tabular}

Adult I. ricinus ticks were removed from cats tested and tested for Bartonella and Rickettsia by PCR. Rickettsia species were identified by RLB. For Bartonella, the PCR products of $380 \mathrm{bp}$ were sequenced and analysed. Six ticks were positive for both $R$. helvetica and Bartonella-related sp..

the PCR products of 72 lysates (75\%) yielded a $380 \mathrm{bp}$ on the agarose gels. Sequencing revealed that at least 26 ticks contained DNA identical to B. schoenbuchensis (AJ564632), and 13 ticks contained the Bartonellarelated sp. Sequencing was not successful in all cases, probably also because of mixed sequences of both Bartonella-related sp and B. schoenbuchensis (not shown). As $B$. schoenbuchensis was never detected in questing ticks (Table 1), we wondered how B. schoenbuchensis was transmitted between red deer. In the literature, deer keds (Lipoptena cervi) have been suggested to transmit $B$. schoenbuchensis between red deer as they have shown to be infected with B. schoenbuchensis [64]. We tested whether this was also the case in the Netherlands. For this, 56 deer keds were collected, lysed and a PCR on part of the gltA gene was performed. 46 deer keds were found to be positive of B. schoenbuchensis (AJ564632).

\section{Tissue samples from rodents}

The origin of the Bartonella-related sp. from questing ticks was further investigated. One of the most prominent vertebrate hosts of I. ricinus are probably rodents. To determine whether mice are a potential reservoir of this Bartonella-related sp., 96 DNA samples from ear tissue of small rodents, Myodes glareolus and A. sylvaticus, from the Duin en Kruidberg area were tested by PCR and sequencing a $380 \mathrm{bp}$ part of the gltA gene. Twelve rodent samples were positive, but sequencing revealed that these sequences $(\mathrm{n}=5)$ were $98-99 \%$ similar to Bartonella isolates from A. flavicollis (yellownecked mouse) from Slovenia (347 bp, DQ155393) and Greece (338 bp, AY435110). The Bartonella sequences from these rodents were only $70 \%$ similar to the Bartonella-related sp. from questing ticks (Figure 2).

\section{Fleas from rodents}

PCR of the gltA-gene on 24 flea lysates from wild rodents, $M$. glareolus and $A$. sylvaticus, caught in the Netherlands revealed that the Bartonella sp. found in $A$. sylvaticus was similar to those found in their fleas (Figure 2). Since the Bartonella sequences found in mouse were similar to those found in their fleas, but not similar to the Bartonella sequences found in questing I. ricinus ticks, these data suggested that the Bartonella found in rodents are most likely transmitted via fleas, not ticks.

\section{Fleas from pet animals}

Although the DNA of a laboratory B. henselae strain was used as a positive control, we wondered whether the gltA PCR was specific and sensitive enough to detect $B$. henselae in questing ectoparasites. For this, fleas collected from pets were also tested under the same conditions as the tick lysates for both Bartonella and Rickettsia. 32 of 204 pools of cat fleas (Ctenocephalides felis) were positive for $B$. henselae. Three pools were positive for B. clarridgeiae and 43 pools for R. felis (Table 3). The identity of the latter two was confirmed by PCR and sequencing parts of the $16 \mathrm{~S}$ rRNA and gltA genes, respectively (Figure 1). In one out of 17 pools of dog fleas (Ctenocephalides canis) DNA of $R$. felis was detected. No Bartonella sp. was detected in dog fleas. One third of the sampled dogs $(\mathrm{n}=44)$ and cats $(\mathrm{n}=$ 109) carried fleas positive for $R$. felis, and one sixth of the animals had fleas positive for B. henselae (Table 4). Three cats had fleas positive for B. clarridgeiae.

\section{Discussion}

One of the major aims of this study was to investigate whether questing I. ricinus ticks transmit Bartonella species, particularly $B$. henselae, to humans $[31,65,66]$. In the 1719 questing ticks that were analysed, $B$. henselae was not found (Table 1). A gltA sequence, which was found in approximately $10 \%$ of the nymph and adult ticks, was closely related to a sequence found in I. scapularis ticks [67]. This sequence was designated previously as a Bartonella sp.. Phylogenetic analysis showed that the gltA sequence of this Bartonellarelated species did not cluster with other Bartonella species (Figure 2). Furthermore, this Bartonella-related sequence was also found in lysates from 41 of 192 questing I. ricinus larvae, implying that the sequence is either from an environmental contamination or from a microorganism that is transmitted transovarially. To

\section{Table 3 Pathogens found in fleas from pets}

\begin{tabular}{lll}
\hline & C. canis & C. felis \\
\hline Total (number) & 48 & 528 \\
Pools (size) & $17(1-7)$ & $204(1-17)$ \\
B. henselae-positive (pools) & 0 & 32 \\
B. clarridgeiae-positive (pools) & 0 & 3 \\
R. felis-positive (pools) & 1 & 43 \\
\hline
\end{tabular}

Ctenocephalides canis and C. felis fleas were separated based on morphological markers and were pooled per animal and flea species. In several cases more than one pool per animal was taken. Fleas were analysed by PCR and sequencing for the presence or absence of DNA from Bartonella and Rickettsia species. 
Table 4 Prevalence of pets with fleas carrying zoonotic pathogens

\begin{tabular}{lll}
\hline & Dogs & Cats \\
\hline Total & 44 & 109 \\
R. felis & $13(30 \%)$ & $34(31 \%)$ \\
B. henselae & $7(16 \%)$ & $17(16 \%)$ \\
B. clarridgeiae & 0 & $3(3 \%)$ \\
R. felis \&B. henselae & 2 & 3 \\
\hline
\end{tabular}

Data are from Table 3, but now presented as prevalence in cats and dogs with fleas.

the best of our knowledge, transovarial transmission of Bartonella has never been demonstrated. Our data support this: B. schoenbuchensis was found in $75 \%$ of the adult ticks feeding on deer, but never in the questing larvae or nymphs tested in this study. We conclude that it is unlikely that the Bartonella-related sequence found in ticks is from a Bartonella species. Instead, we propose that the gltA sequence found in the questing I. ricinus ticks is from "Ca. Midichloria mitochondrii", an endosymbiont found in various hard ticks, including I. ricinus [61]. Only a few genes, but not the gltA gene, of this microorganism have been amplified and sequenced [68]. The presence of " $\mathrm{Ca}$. Midichloria mitochondrii" in Dutch $I$. ricinus ticks was shown here by PCR and sequencing part of its $16 \mathrm{~S}$ rRNA gene (Figure 2). "Ca. Midichloria mitochondrii" is present in mitochondria of tick cells and cannot be isolated or cultured. However, it cannot be excluded that the gltA gene isolated from tick lysates is unrelated to " $\mathrm{Ca}$. Midichloria mitochondrii".

In this study, we have identified several Bartonella species: B. henselae and B. clarridgeiae, B. grahamii and another rodent-related Bartonella species and B. schoenbuchensis. As far as we know, the presence of these Bartonella species in the Netherlands is described here for the first time, except for B. henselae [69]. None of these were detected in this study in questing $I$. ricinus ticks. Statistically, less than $0.2 \%$ of the questing ticks might be infected with $B$. henselae or any other Bartonella species (95\% exact binomial confidence interval). Therefore the risk of contracting bartonellosis from I. ricinus ticks in the Netherlands seems to be very low.

Questing I. ricinus larvae were subjected to PCR using generic primers on the $16 \mathrm{~S}$ rRNA of Bartonella species [64]. Five of these samples were positive and yielded 5 identical sequences which were $99 \%$ similar to a plethora of uncultured bacteria in Genbank, varying from an uncultured Bartonella isolated from the gut of Apis mellifera mellifera, Phyllobacterium myrsinacearum to a presumed Bartonella grahamii. This high variety of hits indicates that the 16S rRNA gene has too little resolution power to positively identify a Bartonella species or to distinguish Bartonella from other, closely related genera. Furthermore, results of a BLAST depend on the quality of sequences in the database. In an earlier publication we discussed the pitfalls of using a database with only verified sequence types which neglects large amounts of less well verified but valuable data [70]. Using a large and freely accessible database like that of NCBI, however, has its own pitfalls as the quality of submitted sequences is not always good and identities of sequenced species are not always verified. Bartonella sp., Rickettsia sp. and "Ca. Midichloria mitochondrii" are very difficult to culture and some species have not yet been cultured at all. For uncultured microorganisms often only a limited number of genes are known and based on the limited data available it can be difficult to identify a microorganism to genus level. This can lead to misnaming of database entries which in turn can lead to further misidentifications [70].

While ticks seem to play a negligible role in Bartonella transmission, other ectoparasites, especially fleas, might be involved in the enzootic cycle of Bartonella in animals. B. henselae and B. clarridgeiae were found in cat fleas, and B. grahamii and another rodent-related Bartonella species were found in fleas collected from rodents, and B. schoenbuchensis in deer keds. All these ectoparasites could transmit Bartonella between animals and maybe also from animals to humans. B. henselae is well known to be associated to human cases of bartonellosis in the form of cat scratch disease $[7,8]$. It is mainly transmitted directly from cats to humans but might also be transmitted by infected cat fleas [19]. To date, including the current study, the transmission of $B$. henselae to humans via ticks has not been proven and the risk of transmission by tick is probably negligible [71]. B. clarridgeiae has also been frequently reported from cats and their ectoparasites $[17,72]$ but has so far only incidentally been reported from human cases [20,22]. Cat fleas could play a role in $B$. clarridgeiae transmission but the route of transmission has not yet been established.

B. schoenbuchensis has been hypothesized to be involved in the development of deer ked dermatitis, a sometimes long-lasting skin condition following bites of deer keds [73]. While the exposure of the general population to deer keds is rather low, some specific groups like forest workers and hunters are at high risk to be bitten by these arthropods. In this limited population, deer keds might play a role in transmission of $B$. schoenbuchensis. In the general population exposure to $B$. henselae is much more likely than exposure to any of the other discussed Bartonella species. It is therefore also likely to cause most bartonellosis cases. Further research is necessary to determine the risk of zoonotic transmission of different Bartonella species upon a bite of cat fleas and other arthropods. 


\section{Conclusions}

Risk of human bartonellosis transmitted by I. ricinus ticks is negligible while other arthropods, including deer keds and fleas, can potentially transmit Bartonella sp. to humans. Earlier reports of high infection rates of questing ticks with a Bartonella species might in fact be due to the misidentification of " $\mathrm{Ca}$. Midichloria mitochondrii" as Bartonella sp..

\section{Acknowledgements}

The authors are very grateful to the volunteers and co-workers of the Central Veterinary Institute (Cor Gaasenbeek, Fred Borgsteede and Kitty Maassen) of Wageningen University who have dedicated much time and effort to monthly collections of ticks. We thank Marieta Braks for initial flea identification, Annelies van Goor and her dedicated students, particularly Rudy Muts, for collecting fleas from pet animals and Marieke Mensink, Sabine van Dijk, Christa Drenth and Tineke Bolleman for their excellent technical assistance. We are very grateful to the veterinary practices who participated in collecting fleas and ticks from pets. We are indebted to Margriet Montizaan (Dutch Royal Hunting Society, Amersfoort) for collecting deer keds. This study was financially supported by the Dutch Food and Consumer Product Safety Authority (NWA) and by the Ministry of Health, Welfare and Sport (VWS)

\section{Author details}

'Laboratory for Zoonoses and Environmental Microbiology, National Institute for Public Health and Environment (RIVM), Bilthoven, The Netherlands. ${ }^{2}$ Laboratory for Infectious Diseases and Screening, National Institute for Public Health and Environment (RIVM), Bilthoven, The Netherlands. ${ }^{3}$ Laboratory of Entomology, Wageningen University, Wageningen, The Netherlands. ${ }^{4}$ Companion Animal Hospital 't Heike, Veldhoven, The Netherlands. ${ }^{5}$ Institute for Risk Assessment Sciences, Division of Veterinary Public Health, Utrecht University, Utrecht, The Netherlands. ${ }^{6}$ Utrecht Centre for Tick-borne Diseases (UCTD), Department of Infectious Diseases and Immunology, Faculty of Veterinary Medicine, Utrecht University, Utrecht, The Netherlands. IInstitute for Parasitology and Tropical Veterinary Medicine, Freie Universität Berlin, Berlin, Germany.

\section{Authors' contributions}

FJ, WT, JRR, HS and PAMO were involved in study design. FG, EKEH, AMN and $\mathrm{PO}$ collected ticks and fleas, contributed to laboratory analyses and analyzed data. ETK and MF developed new methodology, performed laboratory analyses and analyzed data. HS acquired funding, was involved in data analyses and wrote the initial draft. ETK performed phylogenetic analyses and wrote the final draft. All authors were involved in completing the manuscript and approved the final version

\section{Competing interests}

The authors declare that they have no competing interests.

Received: 14 February 2011 Accepted: 18 April 2011

Published: 18 April 2011

\section{References}

1. McElroy KM, Blagburn BL, Breitschwerdt EB, Mead PS, McQuiston JH: Fleaassociated zoonotic diseases of cats in the USA: bartonellosis, flea-borne rickettsioses, and plague. Trends Parasitol 2010, 26:197-204.

2. Salzberger B, Franzen C, Fatkenheuer G: [Update in infectious diseases. Part I: epidemiology]. Med Klin (Munich) 2000, 95:314-320.

3. Carithers HA: Cat-scratch disease. An overview based on a study of 1,200 patients. Am J Dis Child 1985, 139:1124-1133.

4. Loutit JS: Bartonella infections. Curr Clin Top Infect Dis 1997, 17:269-290.

5. Margileth AM, Wear DJ, English CK: Systemic cat scratch disease: report of 23 patients with prolonged or recurrent severe bacterial infection. $J$ Infect Dis 1987, 155:390-402.

6. Wheeler SW, Wolf SM, Steinberg EA: Cat-scratch encephalopathy. Neurology 1997, 49:876-878
7. Maman E, Bickels J, Ephros M, Paran D, Comaneshter D, Metzkor-Cotter E, Avidor B, Varon-Graidy M, Wientroub S, Giladi M: Musculoskeletal manifestations of cat scratch disease. Clin Infect Dis 2007, 45:1535-1540.

8. Giladi M, Maman E, Paran D, Bickels J, Comaneshter D, Avidor B, VaronGraidy M, Ephros M, Wientroub S: Cat-scratch disease-associated arthropathy. Arthritis Rheum 2005, 52:3611-3617.

9. Houpikian P, Raoult D: Blood culture-negative endocarditis in a reference center: etiologic diagnosis of 348 cases. Medicine (Baltimore) 2005, 84:162-173.

10. Lamas CC, Eykyn SJ: Blood culture negative endocarditis: analysis of 63 cases presenting over 25 years. Heart 2003, 89:258-262.

11. Fournier PE, Thuny F, Richet H, Lepidi H, Casalta JP, Arzouni JP, Maurin M, Celard M, Mainardi JL, Caus T, et al: Comprehensive diagnostic strategy for blood culture-negative endocarditis: a prospective study of 819 new cases. Clin Infect Dis 2010, 51:131-140.

12. Welch DF, Pickett DA, Slater LN, Steigerwalt AG, Brenner DJ: Rochalimaea henselae sp. nov., a cause of septicemia, bacillary angiomatosis, and parenchymal bacillary peliosis. J Clin Microbiol 1992, 30:275-280.

13. Koehler JE, Glaser CA, Tappero JW: Rochalimaea henselae infection. A new zoonosis with the domestic cat as reservoir. Jama 1994, 271:531-535.

14. Regnery R, Martin M, Olson J: Naturally occurring "Rochalimaea henselae" infection in domestic cat. Lancet 1992, 340:557-558.

15. Kordick DL, Wilson KH, Sexton DJ, Hadfield TL, Berkhoff HA, Breitschwerdt EB: Prolonged Bartonella bacteremia in cats associated with cat-scratch disease patients. J Clin Microbiol 1995, 33:3245-3251.

16. Bergmans AM, de Jong CM, van Amerongen G, Schot CS, Schouls LM: Prevalence of Bartonella species in domestic cats in The Netherlands. J Clin Microbiol 1997, 35:2256-2261.

17. Rolain JM, Franc M, Davoust B, Raoult D: Molecular detection of Bartonella quintana, B. koehlerae, B. henselae, B. clarridgeiae, Rickettsia felis, and Wolbachia pipientis in cat fleas, France. Emerg Infect Dis 2003, 9:338-342.

18. Shaw SE, Kenny MJ, Tasker S, Birtles RJ: Pathogen carriage by the cat flea Ctenocephalides felis (Bouche) in the United Kingdom. Vet Microbiol 2004, 102:183-188

19. Zangwill KM, Hamilton DH, Perkins BA, Regnery RL, Plikaytis BD, Hadler JL, Cartter ML, Wenger JD: Cat scratch disease in Connecticut. Epidemiology, risk factors, and evaluation of a new diagnostic test. N Engl J Med 1993, 329:8-13.

20. Sander A, Zagrosek A, Bredt W, Schiltz E, Piemont Y, Lanz C, Dehio C: Characterization of Bartonella clarridgeiae flagellin (FlaA) and detection of antiflagellin antibodies in patients with lymphadenopathy. J Clin Microbiol 2000, 38:2943-2948.

21. Eremeeva ME, Gerns HL, Lydy SL, Goo JS, Ryan ET, Mathew SS, Ferraro MJ, Holden JM, Nicholson WL, Dasch GA, Koehler JE: Bacteremia, fever, and splenomegaly caused by a newly recognized bartonella species. N Engl J Med 2007, 356:2381-2387.

22. Kordick DL, Hilyard EJ, Hadfield TL, Wilson KH, Steigerwalt AG, Brenner DJ, Breitschwerdt EB: Bartonella clarridgeiae, a newly recognized zoonotic pathogen causing inoculation papules, fever, and lymphadenopathy (cat scratch disease). J Clin Microbiol 1997, 35:1813-1818.

23. Kerkhoff FT, Bergmans AM, van Der Zee A, Rothova A: Demonstration of Bartonella grahamii DNA in ocular fluids of a patient with neuroretinitis. J Clin Microbiol 1999, 37:4034-4038.

24. Hofhuis A, van der Giessen JW, Borgsteede FH, Wielinga PR, Notermans DW, van Pelt W: Lyme borreliosis in the Netherlands: strong increase in GP consultations and hospital admissions in past 10 years. Euro Surveill 2006, 11, E060622 060622.

25. Vilcins IM, Kosoy M, Old JM, Deane EM: Bartonella-like DNA detected in Ixodes tasmani ticks (Acari: Ixodida) infesting Koalas (Phascolarctos cinereus) in Victoria, Australia. Vector Borne Zoonotic Dis 2009, 9:499-503.

26. Chang CC, Chomel BB, Kasten RW, Romano V, Tietze N: Molecular evidence of Bartonella spp. in questing adult Ixodes pacificus ticks in California. J Clin Microbiol 2001, 39:1221-1226.

27. Angelakis E, Billeter SA, Breitschwerdt EB, Chomel BB, Raoult D: Potential for tick-borne bartonelloses. Emerg Infect Dis 16:385-391.

28. Reye AL, Hubschen JM, Sausy A, Muller CP: Prevalence and seasonality of tick-borne pathogens in questing Ixodes ricinus ticks from Luxembourg. Appl Environ Microbiol 76:2923-2931.

29. Dietrich F, Schmidgen T, Maggi RG, Richter D, Matuschka FR, Vonthein R, Breitschwerdt EB, Kempf VA: Prevalence of Bartonella henselae and 
Borrelia burgdorferi sensu lato DNA in ixodes ricinus ticks in Europe. Appl Environ Microbiol 76:1395-1398.

30. Podsiadly E, Chmielewski T, Sochon E, Tylewska-Wierzbanowska S. Bartonella henselae in Ixodes ricinus ticks removed from dogs. Vector Borne Zoonotic Dis 2007, 7:189-192.

31. Holden K, Boothby JT, Kasten RW, Chomel BB: Co-detection of Bartonella henselae, Borrelia burgdorferi, and Anaplasma phagocytophilum in Ixodes pacificus ticks from California, USA. Vector Borne Zoonotic Dis 2006, 6:99-102.

32. Morozova OV, Cabello FC, Dobrotvorsky AK: Semi-nested PCR detection of Bartonella henselae in Ixodes persulcatus ticks from Western Siberia, Russia. Vector Borne Zoonotic Dis 2004, 4:306-309.

33. Cotte V, Bonnet $\mathrm{S}$, Le Rhun D, Le Naour E, Chauvin A, Boulouis HJ, Lecuelle B, Lilin T, Vayssier-Taussat M: Transmission of Bartonella henselae by Ixodes ricinus. Emerg Infect Dis 2008, 14:1074-1080.

34. Telford SR, Wormser GP: Bartonella spp. transmission by ticks not established. Emerg Infect Dis 16:379-384.

35. Heyman P, Cochez C, Hofhuis A, van der Giessen J, Sprong H, Porter SR Losson B, Saegerman C, Donoso-Mantke O, Niedrig M, Papa A: A clear and present danger: tick-borne diseases in Europe. Expert Rev Anti Infect Ther 2010, 8:33-50

36. Parola P, Paddock CD, Raoult D: Tick-borne rickettsioses around the world: emerging diseases challenging old concepts. Clin Microbiol Rev 2005, 18:719-756.

37. Sprong $\mathrm{H}$, Wielinga PR, Fonville $\mathrm{M}$, Reusken $\mathrm{C}$, Brandenburg $\mathrm{AH}$, Borgsteede F, Gaasenbeek C, van der Giessen JW: Ixodes ricinus ticks are reservoir hosts for Rickettsia helvetica and potentially carry flea-borne Rickettsia species. Parasit Vectors 2009, 2:41.

38. Tijsse-Klasen E, Fonville M, Reimerink JH, Spitzen-van der Sluijs A, Sprong H: Role of sand lizards in the ecology of Lyme and other tick-borne diseases in the Netherlands. Parasit Vectors 2010, 3:42.

39. Nielsen H, Fournier PE, Pedersen IS, Krarup H, Ejlertsen T, Raoult D: Serological and molecular evidence of Rickettsia helvetica in Denmark. Scand J Infect Dis 2004, 36:559-563.

40. Fournier PE, Allombert C, Supputamongkol Y, Caruso G, Brouqui $P$, Raoult D: Aneruptive fever associated with antibodies to Rickettsia helvetica in Europe and Thailand. J Clin Microbiol 2004, 42:816-818.

41. Nilsson K: Septicaemia with Rickettsia helvetica in a patient with acute febrile illness, rash and myasthenia. J Infect 2009, 58:79-82.

42. Nilsson K, Lindquist O, Pahlson C: Association of Rickettsia helvetica with chronic perimyocarditis in sudden cardiac death. Lancet 1999, 354:1169-1173.

43. Nilsson K, Liu A, Pahlson C, Lindquist O: Demonstration of intracellular microorganisms (Rickettsia spp., Chlamydia pneumoniae, Bartonella spp.) in pathological human aortic valves by PCR. J Infect 2005, 50:46-52.

44. Nilsson K, Pahlson C, Lukinius A, Eriksson L, Nilsson L, Lindquist O: Presence of Rickettsia helvetica in granulomatous tissue from patients with sarcoidosis. J Infect Dis 2002, 185:1128-1138.

45. Cinco M, Luzzati R, Mascioli M, Floris R, Brouqui P: Serological evidence of Rickettsia infections in forestry rangers in north-eastern Italy. Clin Microbiol Infect 2006, 12:493-495.

46. Fournier PE, Grunnenberger F, Jaulhac B, Gastinger G, Raoult D: Evidence of Rickettsia helvetica infection in humans, eastern France. Emerg Infect Dis 2000, 6:389-392.

47. Nilsson K, Elfving K, Pahlson C: Rickettsia helvetica in patient with meningitis, Sweden, 2006. Emerg Infect Dis 2010, 16:490-492.

48. Reif KE, Macaluso KR: Ecology of Rickettsia felis: a review. J Med Entomol 2009, 46:723-736.

49. Gillespie JJ, Ammerman NC, Beier-Sexton M, Sobral BS, Azad AF: Louseand flea-borne rickettsioses: biological and genomic analyses. Vet Res 2009, 40:12.

50. Galvao MA, Mafra C, Chamone CB, Calic SB, Zavala-Velazquez JE, Walker DH: Clinical and laboratorial evidence of Rickettsia felis infections in Latin America. Rev Soc Bras Med Trop 2004, 37:238-240.

51. Perez-Arellano JL, Fenollar F, Angel-Moreno A, Bolanos M, Hernandez M, Santana E, Hemmersbach-Miller M, Martin AM, Raoult D: Human Rickettsia felis infection, Canary Islands, Spain. Emerg Infect Dis 2005, 11:1961-1964.

52. Oteo JA, Portillo A, Santibanez S, Blanco JR, Perez-Martinez L, Ibarra V: Cluster of cases of human Rickettsia felis infection from Southern Europe (Spain) diagnosed by PCR. J Clin Microbiol 2006, 44:2669-2671.
53. Perez-Osorio CE, Zavala-Velazquez JE, Arias Leon JJ, Zavala-Castro JE: Rickettsia felis as emergent global threat for humans. Emerg Infect Dis 2008, 14:1019-1023.

54. Renvoise A, Joliot AY, Raoult D: Rickettsia felis infection in man, France. Emerg Infect Dis 2009, 15:1126-1127.

55. Black WCt, Piesman J: Phylogeny of hard- and soft-tick taxa (Acari: Ixodida) based on mitochondrial $16 \mathrm{~S}$ rDNA sequences. Proc Natl Acad Sci USA 1994, 91:10034-10038.

56. Wielinga PR, Gaasenbeek C, Fonville M, de Boer A, de Vries A, Dimmers W, Akkerhuis Op Jagers G, Schouls LM, Borgsteede F, van der Giessen JW: Longitudinal analysis of tick densities and Borrelia, Anaplasma, and Ehrlichia infections of Ixodes ricinus ticks in different habitat areas in The Netherlands. Appl Environ Microbiol 2006, 72:7594-7601.

57. Bergmans AM, Peeters MF, Schellekens JF, Vos MC, Sabbe LJ, Ossewaarde JM, Verbakel H, Hooft HJ, Schouls LM: Pitfalls and fallacies of cat scratch disease serology: evaluation of Bartonella henselae-based indirect fluorescence assay and enzyme-linked immunoassay. J Clin Microbiol 1997, 35:1931-1937.

58. Garcia-Esteban C, Gil H, Rodriguez-Vargas M, Gerrikagoitia X, Barandika J, Escudero R, Jado I, Garcia-Amil C, Barral M, Garcia-Perez AL, et al: Molecular method for Bartonella species identification in clinical and environmental samples. J Clin Microbiol 2008, 46:776-779.

59. De Sousa R, Edouard-Fournier P, Santos-Silva M, Amaro F, Bacellar F, Raoult D: Molecular detection of Rickettsia felis, Rickettsia typhi and two genotypes closely related to Bartonella elizabethae. Am J Trop Med Hyg 2006, 75:727-731.

60. Beninati T, Lo N, Sacchi L, Genchi C, Noda H, Bandi C: A novel alphaProteobacterium resides in the mitochondria of ovarian cells of the tick Ixodes ricinus. Appl Environ Microbiol 2004, 70:2596-2602.

61. Sassera D, Beninati T, Bandi C, Bouman EA, Sacchi L, Fabbi M, Lo N: 'Candidatus Midichloria mitochondrii', an endosymbiont of the tick Ixodes ricinus with a unique intramitochondrial lifestyle. Int I Syst Evol Microbiol 2006, 56:2535-2540

62. Christova I, Van De Pol J, Yazar S, Velo E, Schouls L: Identification of Borrelia burgdorferi sensu lato, Anaplasma and Ehrlichia species, and spotted fever group Rickettsiae in ticks from Southeastern Europe. Eur J Clin Microbiol Infect Dis 2003, 22:535-542.

63. Schouls LM, Van De Pol I, Rijpkema SG, Schot CS: Detection and identification of Ehrlichia, Borrelia burgdorferi sensu lato, and Bartonella species in Dutch Ixodes ricinus ticks. J Clin Microbiol 1999, 37:2215-2222.

64. Matsumoto K, Berrada ZL, Klinger E, Goethert HK, Telford SR: Molecular detection of Bartonella schoenbuchensis from ectoparasites of deer in Massachusetts. Vector Borne Zoonotic Dis 2008, 8:549-554.

65. Dietrich F, Schmidgen T, Maggi RG, Richter D, Matuschka FR, Vonthein R, Breitschwerdt EB, Kempf VA: Prevalence of Bartonella henselae and Borrelia burgdorferi sensu lato DNA in ixodes ricinus ticks in Europe. Appl Environ Microbiol 2010, 76:1395-1398.

66. Angelakis E, Pulcini C, Waton J, Imbert P, Socolovschi C, Edouard S, Dellamonica P, Raoult D: Scalp eschar and neck lymphadenopathy caused by Bartonella henselae after Tick Bite. Clin Infect Dis 2010, 50:549-551.

67. Swanson Kl, Norris DE: Co-circulating microorganisms in questing Ixodes scapularis nymphs in Maryland. J Vector Ecol 2007, 32:243-251.

68. Epis S, Sassera D, Beninati T, Lo N, Beati L, Piesman J, Rinaldi L, McCoy KD, Torina A, Sacchi L, et al: Midichloria mitochondrii is widespread in hard ticks (Ixodidae) and resides in the mitochondria of phylogenetically diverse species. Parasitology 2008, 135:485-494.

69. Bergmans AM, Schellekens JF, van Embden JD, Schouls LM: Predominance of two Bartonella henselae variants among cat-scratch disease patients in the Netherlands. J Clin Microbiol 1996, 34:254-260.

70. Tijsse-Klasen E, Fonville M, van Overbeek L, Reimerink JH, Sprong H: Exotic Rickettsiae in Ixodes ricinus: fact or artifact? Parasit Vectors 2010, 3:54.

71. Telford SR, Wormser GP: Bartonella spp. transmission by ticks not established. Emerg Infect Dis 2010, 16:379-384.

72. Tsai YL, Lin CC, Chomel BB, Chuang ST, Tsai KH, Wu WJ, Huang CG, Yu JC, Sung MH, Kass PH, Chang CC: Bartonella Infection in Shelter Cats and Dogs and Their Ectoparasites. Vector Borne Zoonotic Dis 2010.

73. Dehio C, Sauder U, Hiestand R: Isolation of Bartonella schoenbuchensis from Lipoptena cervi, a blood-sucking arthropod causing deer ked dermatitis. J Clin Microbiol 2004, 42:5320-5323. 
74. Gassner F, van Vliet AJ, Burgers SL, Jacobs F, Verbaarschot P, Hovius EK, Mulder S, Verhulst NO, van Overbeek LS, Takken W: Geographic and Temporal Variations in Population Dynamics of Ixodes ricinus and Associated Borrelia Infections in The Netherlands. Vector Borne Zoonotic Dis 2010.

doi:10.1186/1756-3305-4-61

Cite this article as: Tijsse-Klasen et al: Absence of zoonotic Bartonella species in questing ticks: First detection of Bartonella clarridgeiae and Rickettsia felis in cat fleas in the Netherlands. Parasites \& Vectors 2011 4:61.

Submit your next manuscript to BioMed Central and take full advantage of:

- Convenient online submission

- Thorough peer review

- No space constraints or color figure charges

- Immediate publication on acceptance

- Inclusion in PubMed, CAS, Scopus and Google Scholar

- Research which is freely available for redistribution

Submit your manuscript at www.biomedcentral.com/submit 